\title{
Role of the Material Electrodes on Resistive Behaviour of Carbon Nanotube-Based Gas Sensors for $\mathrm{H}_{2} \mathrm{~S}$ Detection
}

\author{
M. Lucci, ${ }^{1}$ F. Toschi, ${ }^{2}$ V. Guglielmotti, ${ }^{2}$ S. Orlanducci, ${ }^{2}$ and M. L. Terranova ${ }^{2}$ \\ ${ }^{1}$ Dipartimento di Fisica, Università di Roma "Tor Vergata", Via della Ricerca Scientifica, 00133 Roma, Italy \\ ${ }^{2}$ Dipartimento di Scienze e Tecnologie Chimiche, Minimalab Università di Roma "Tor Vergata", Via della Ricerca Scientifica, \\ 00133 Roma, Italy
}

Correspondence should be addressed to F. Toschi, francesco.toschi@uniroma2.it

Received 24 January 2012; Revised 20 March 2012; Accepted 4 April 2012

Academic Editor: Michele Penza

Copyright () 2012 M. Lucci et al. This is an open access article distributed under the Creative Commons Attribution License, which permits unrestricted use, distribution, and reproduction in any medium, provided the original work is properly cited.

Miniaturized gas-sensing devices that use single-walled carbon nanotubes as active material have been fabricated using two different electrode materials, namely, $\mathrm{Au} / \mathrm{Cr}$ and $\mathrm{NbN}$. The resistive sensors have been assembled aligning by dielectrophoresis the nanotube bundles between $40 \mu \mathrm{m}$ spaced $\mathrm{Au} / \mathrm{Cr}$ or NbN multifinger electrodes. The sensing devices have been tested for detection of the $\mathrm{H}_{2} \mathrm{~S}$ gas, in the concentration range 10-100 ppm, using $\mathrm{N}_{2}$ as carrier gas. No resistance changes were detected using sensor fabricated with $\mathrm{NbN}$ electrodes, whereas the response of the sensor fabricated with $\mathrm{Au} / \mathrm{Cr}$ electrodes was characterized by an increase of the resistance upon gas exposure. The main performances of this sensor are a detection limit for $\mathrm{H}_{2} \mathrm{~S}$ of $10 \mathrm{ppm}$ and a recovery time of few minutes. The present study suggests that the mechanism involved in $\mathrm{H}_{2} \mathrm{~S}$ gas detection is not a direct charge transfer between molecules and nanotubes. The hypothesis is that detection occurs through passivation of the Au surfaces by $\mathrm{H}_{2} \mathrm{~S}$ molecules and modification of the contact resistance at the Au/nanotube interface.

\section{Introduction}

Among the many new technology opportunities and scientific challenges provided by carbon nanotubes (CNT), the sensing represents one of the most important topic. In particular, the design and fabrication of gas sensors assembled with CNT is a burgeoning research field still under development. The gas-sensing devices based on carbon nanomaterials can operate by a variety of different mechanism, such as resistivity change, capacitive effects, field-effect, and gas ionization $[1,2]$. The resistive sensors, based on the property of some materials to modify their conductivity when in contact with chemical species, represent nowadays the most widespread class of gas sensors [3].

The intrinsic properties of CNTs meet indeed totally the requirements for a chemical sensor in terms of sensitivity, reproducibility, and durability $[4,5]$, whereas chemi$\mathrm{cal} / \mathrm{physical}$ modifications of the nanotube walls can enhance the molecular specificity, making it possible to achieve a good selectivity [6].
Moreover the use of the carbon nanotubes as active sensing material for gas detection enables to minimize size/weight of the device, with reduction of power consumption and of manufacturing costs.

In our labs researches related to gas detection are carried out using resistive sensors assembled with single wall carbon nanotubes (SWCNTs) [7-9]. The experiments performed up to now demonstrated that such sensors are able to detect at room temperature sub-ppm levels of gas molecules (NO, $\mathrm{NO}_{2}$, and $\mathrm{NH}_{3}$ ) in some hundreds of $\mu$ s. Moreover, after only few seconds, the devices are ready for a new operation. To reach such good performances, the main challenges to be managed are the relative orientation of the nanotubes and the application of a back-gate voltage [7-9].

The task of optimizing the organization of the SWCNT between the conductive stripes has been faced and successfully achieved by means of an dielectrophoresis process (DEP) that induces alignment of the SWCNT bundles between the electrodes [10]. A series of experiments confirmed that this kind of nanotube organization is indeed 
strictly needed in order to increase the sensitivity of the device. The second task regards a proper tuning of the voltages applied to the back-gate contact during the various phases of the nanotube/gas interaction processes. The voltage tuning was found to strongly improve the response times and to allow sensor self-calibration.

In resistive devices the p-type semiconducting behaviour of SWCNT is exploited to discriminate species with different electronic properties; an electron-donor gas affects the conductivity in opposite way with respect to an electronacceptor gas. In this contest the material of the electrode was assumed not to influence the sensor response.

However, it was noted [11] that the response of the SWCNT-based sensor was influenced by the nature of the electrode metallic material, and it was suggested that the interface between the nanotubes and the metal could play an important role in the response of the resistive sensors. This finding could open the way to a selective sensing, obtained by the use of different electrode materials.

In this context we felt it worthwhile to fabricate nanotube-based devices with electrodes made by different materials and to test their detecting performances for the $\mathrm{H}_{2} \mathrm{~S}$ gas. In the present study devices with electrodes made by $\mathrm{Au} / \mathrm{Cr}$ and $\mathrm{NbN}$ were used.

The choice of $\mathrm{NbN}$, a rather unconventional material for a gas sensor, was made because we asked for a second material with a work function (WF) value quite similar to that of $\mathrm{Au}(\mathrm{WF}=5,1 \mathrm{eV})$, but unable to chemically interact with S-containing species. Based on these requirements, the preference went to $\mathrm{NbN}(\mathrm{WF}=4.95 \mathrm{eV})$ [12], that is, chemically stable, also against oxidation, [13] and mechanically resistant.

$\mathrm{H}_{2} \mathrm{~S}$ is a flammable, dangerous, and reactive gas originated from soils and from human activities, such as coal combustions and petroleum refining. The levels of personal exposure that workers may receive range between 100 and 250 ppm [14].

Accurate and rapid detection of hydrogen sulphide is needed for safety reasons and environmental pollution control [15]. The sensing devices presently in use are rather bulky and expensive and moreover tend easily to saturate. There is therefore a pressing need of technological improvements for portable detectors with fast response for the identification of such a gas.

\section{Experimental}

The sensor consists in a field emission transistor (FET)-like 3-pin multifinger element having an infinite electrical resistance, that starts to drop when the nanotubes are deposited between the interdigitated electrode stripes. The resistance is measured between drain-source pins, and the gate is used to improve the desorption rate.

Two kinds of materials, namely, $\mathrm{Au} / \mathrm{Cr}$ and $\mathrm{NbN}$, were employed to fabricate the microelectrodes. $\mathrm{Au} / \mathrm{Cr}(\mathrm{Cr}$ is the adhesive layer) or $\mathrm{NbN}$ films were deposited on the $\mathrm{SiO}_{2}$ insulating layers grown on a p-doped $\mathrm{Si}$ substrate. The Au and $\mathrm{Cr}$ deposits (thickness: $80 \mathrm{~nm}$ and $20 \mathrm{~nm}$, resp.) were

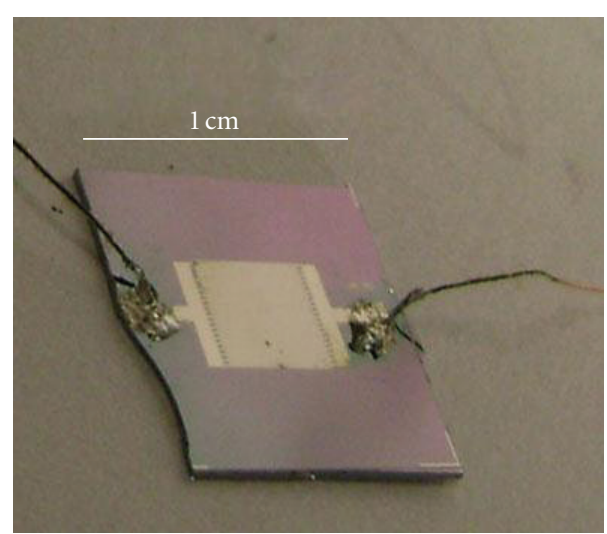

FIGURE 1: Optical image of the tested sensor.

produced by thermal evaporation of solid targets, the $\mathrm{NbN}$ deposits by DC-reactive sputtering, following an already established procedure [16].

The interdigitated microelectrodes, $40 \mu \mathrm{m}$ spaced, were patterned by a lift-off technique. The dimensions of the sensor are about $1 \times 1 \mathrm{~cm}$ (Figure 1$)$.

The sensing element is realized using controlled amounts of commercial SWCNT (Nanocyl: purity > 90\% wt, diameter: $0.8-1.6 \mathrm{~nm}$, length $5-30 \mu \mathrm{m})$, purified following previously settled procedures [17] and dispersed in $\mathrm{CHCl}_{3}$. The dispersions are sonicated in order to assure a good dispersion of the nanotubes and deposited by casting on the electrode platform within the interdigitated $\mathrm{Au} / \mathrm{Cr}$ or $\mathrm{NbN}$ electrodes.

The alignment of the nanotubes between the electrodes is carried out by means of a dielectrophoretic method. An AC field having a frequency of $1 \mathrm{MHz}$ and $12 \mathrm{~V}_{\mathrm{pp}}$ is applied up to the complete evaporation of the solvent $\left(\mathrm{CHCl}_{3}\right)$. Details have been reported in [9].

The experiments have been performed using a $\mathrm{H}_{2} \mathrm{~S} / \mathrm{N}_{2}$ gas mixture purchased by Rivoira S.p.A. in a tank with a certificated concentration of $100 \mathrm{ppm}$ of $\mathrm{H}_{2} \mathrm{~S}$ in $\mathrm{N}_{2}$. Further dilutions have been obtained by means of a flow meter system. The final $\mathrm{H}_{2} \mathrm{~S}$ concentrations used for the experiments were $10,20,40,60,80$, and $100 \mathrm{ppm}$. The flowing of the gaseous mixtures occurred at $200 \mathrm{sccm}$ for $300 \mathrm{sec}$ under standard conditions $\left(25^{\circ} \mathrm{C}, 1 \mathrm{~atm}\right)$. The desorption processes were carried out applying a back bias of $6 \mathrm{~V}$ for $20 \mathrm{sec}$, coupled with a thermal shock at the temperature of $90^{\circ} \mathrm{C}$ for $15 \mathrm{sec}$.

\section{Results and Discussion}

As shown in Figures 2(a) and 2(b), the DEP process provides a useful way to align SWCNTs between electrodes establishing a good electrical connection to the external measurement circuit.

The alignment of the SWCNTs amplifies the conductance changes of the material when exposed to the gas $[7,9]$. We have firstly tested a multifinger device fabricated with $\mathrm{Au} / \mathrm{Cr}$ stripes. 


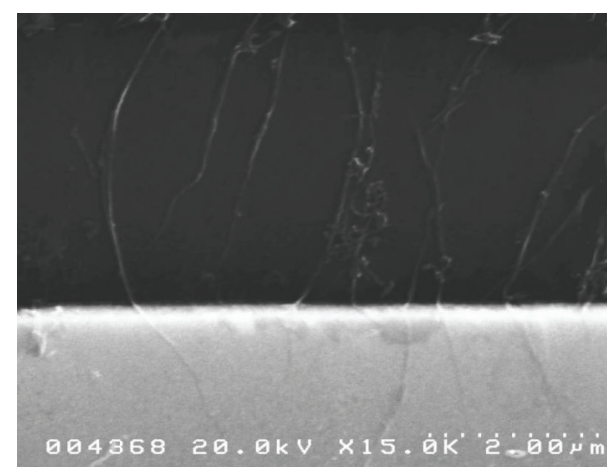

(a)

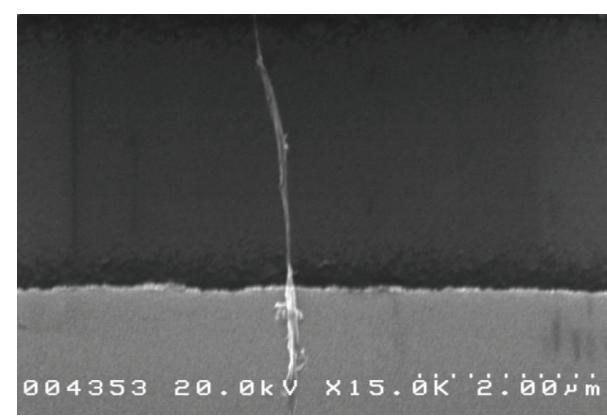

(b)

FIGURE 2: (a) and (b) FE-SEM images of SWCNT bundles aligned between the electrodes of the multifinger device.

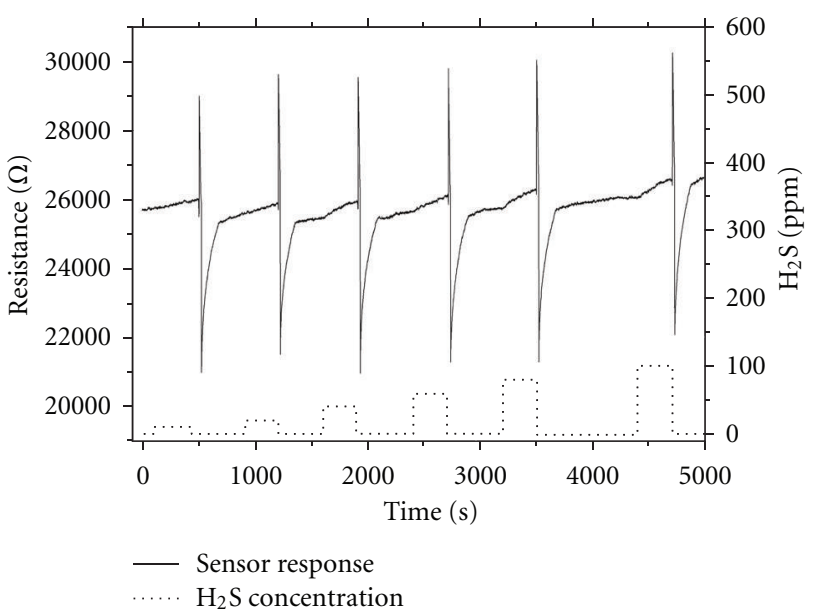

Figure 3: Resistance curves as a function of time for $\mathrm{H}_{2} \mathrm{~S}$ concentrations of $10,20,40,60,80$, and $100 \mathrm{ppm}$ (in $\mathrm{N}_{2}$ ), under standard conditions. The narrow peaks are due to the effect of the applied gate voltage coupled with a thermal shock $\left(90^{\circ} \mathrm{C}\right)$, required for the complete desorption of the gas.

Figure 3 reports the resistance values as a function of time and shows the behaviour of the sensor for $\mathrm{H}_{2} \mathrm{~S}$ concentrations of $10,20,40,60,80$, and $100 \mathrm{ppm}\left(\right.$ in $\mathrm{N}_{2}$ ), measured under standard conditions. The narrow peaks are due to the effect of the applied gate voltage coupled with a thermal shock $\left(90^{\circ} \mathrm{C}\right)$, required for the complete desorption of the gas. Using this approach the recovery time of the sensor was at the longest $5 \mathrm{~min}$ for the higher $\mathrm{H}_{2} \mathrm{~S}$ concentrations.

In order to better visualize the sensor response, we report in Figure 4 for each concentration the relative curve of resistance variation $\left(\Delta R=R_{f}-R_{0}\right)$, where $R_{0}$ is the resistance of the sensor exposed to pure $\mathrm{N}_{2}$, and $R_{f}$ is the maximum value of the resistance. The resistance of the device increases upon exposure to the $\mathrm{H}_{2} \mathrm{~S}$, and the curve is Languimir type. As seen from the graphs of Figure 4, very short response times are obtained, the longest being about $5 \mathrm{~min}$ for the $\mathrm{H}_{2} \mathrm{~S}$ concentration of $100 \mathrm{ppm}$.

The $\Delta R / R_{0}$ data, reported in Figure 5 as a function of the different $\mathrm{H}_{2} \mathrm{~S}$ concentrations, demonstrate a very high precision of the sensor response (see error bars) with a linear trend for concentrations of $\mathrm{H}_{2} \mathrm{~S}$ ranging from 10 to about 60 ppm.

For each concentration 3 measurements have been carried out. The electrical resistance's data and the error bars are obtained by averaging over the 3 measurements. The sensitivity of the sensor is reported in terms of relative resistance change, $\Delta R / R_{0}$.

A different situation occurs using the same sensing material and the same procedures for the assembling of multifinger devices fabricated with $\mathrm{NbN}$ stripes. In this case, independently from the $\mathrm{H}_{2} \mathrm{~S}$ concentration, no signals related to gas adsorption could be detected (Figure 6). The resistance $\left(R_{\mathrm{NbN}}\right)$ of about $13.6 \mathrm{k} \Omega$ shown in Figure 6 is referred to the entire sensor device, that is, the multifingers NbN electrodes interconnected by means of SWCNTs. This $R_{\mathrm{NbN}}$ value obtained enables us to exclude the presence of $\mathrm{Nb}_{2} \mathrm{O}_{5}$ on the metal contacts because, in the case of $\mathrm{Nb}$ oxide formation, a higher value of resistance would be detected. The absence of signals in the presence of $\mathrm{H}_{2} \mathrm{~S}$ deserves some comments.

In general, the resistive response of SWCNT to gaseous species has been interpreted in terms of charge transfer between the p-type semiconducting SWCNT and electrondonors or electron acceptors species [18-21]. In their study, however, Suehiro et al. [11] noted that different electrode materials could modify the response of resistive SWCNTbased sensor and ascribed such behaviour to the occurrence of effects different from the conventional direct gas/nanotube interaction. In the present case too, the absence of resistance variation when using the $\mathrm{NbN}$-based electrodes suggests that no $\mathrm{H}_{2} \mathrm{~S}$ uptake by the nanotubes occurs under our experimental conditions. The fact that the exposure to $\mathrm{H}_{2} \mathrm{~S}$ does not result in a resistance variation when using $\mathrm{NbN}$ electrodes means that the detection of $\mathrm{H}_{2} \mathrm{~S}$ is driven by a mechanism intrinsically different from a electron transfer between nanotubes and adsorbed molecules.

On the basis of the results obtained using different materials for electrode fabrication, it can be argued that the $\mathrm{H}_{2} \mathrm{~S}$ is not directly detected by the Au/Cr-based electrodes through a mechanism of charge transfer between nanotube and gas molecules, as in the case of other species, such as $\mathrm{NOx}$ or $\mathrm{NH}_{3}$, but rather through the modification of the AuSWCNT contact resistance.

A modulation of the Schottky barrier is thought to take place between the gold electrode and SWCNTs when exposed 


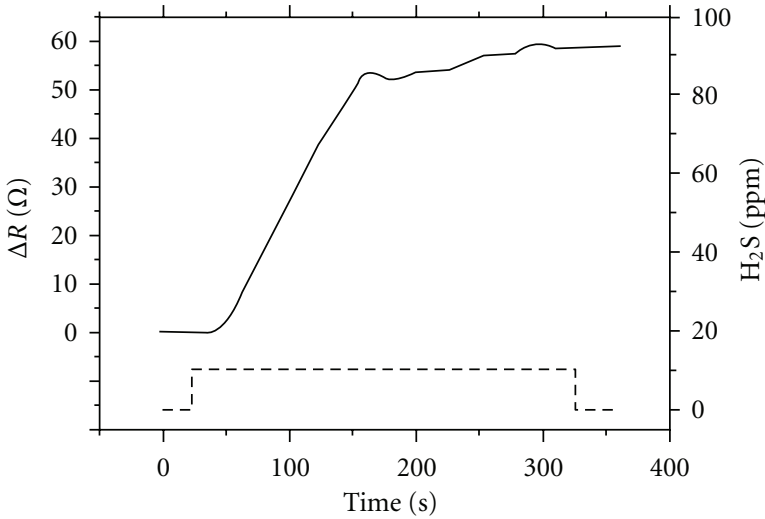

(a)

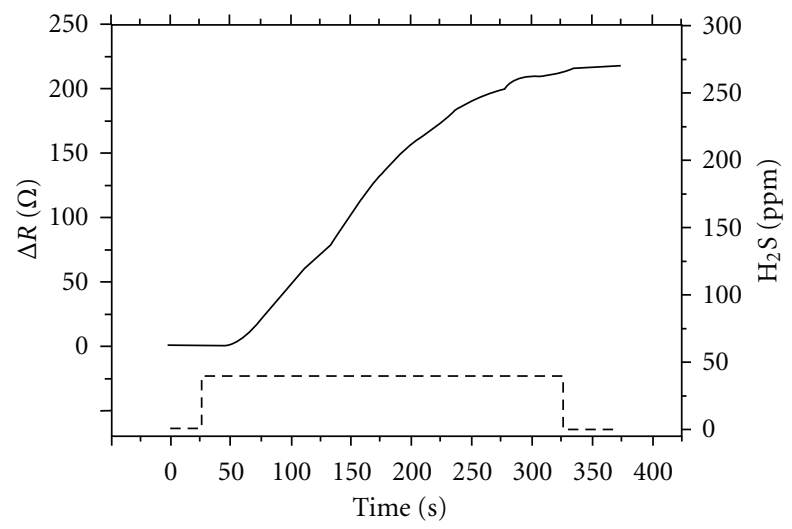

(c)

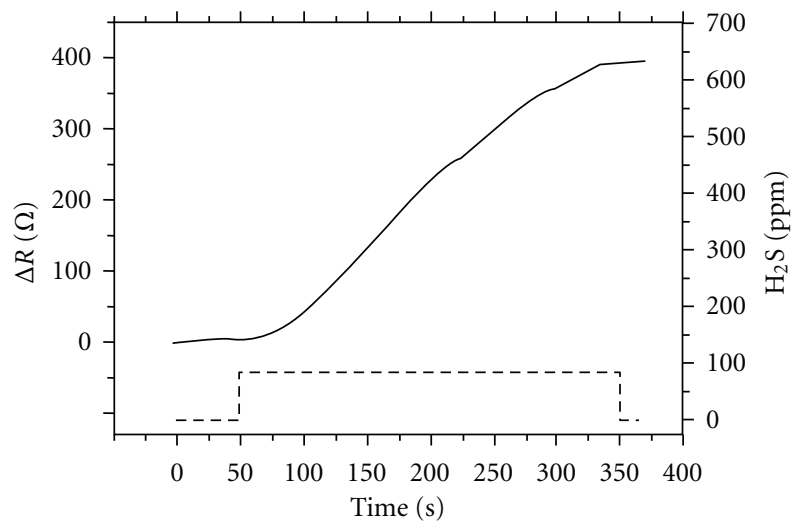

(e)

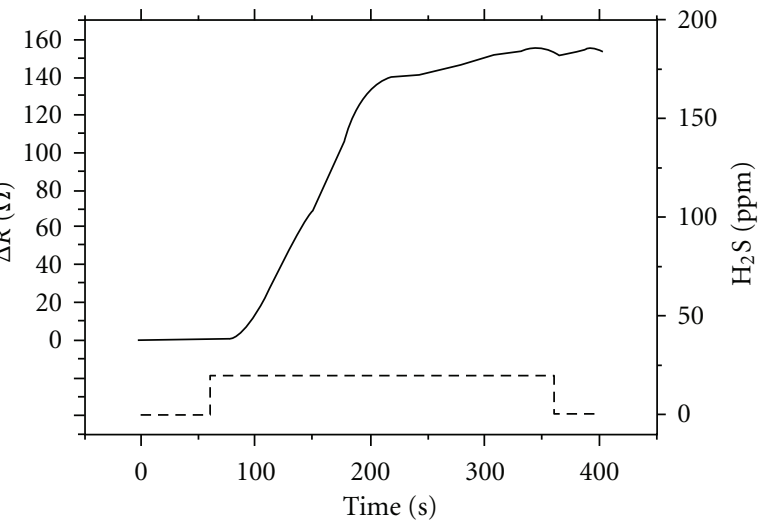

(b)

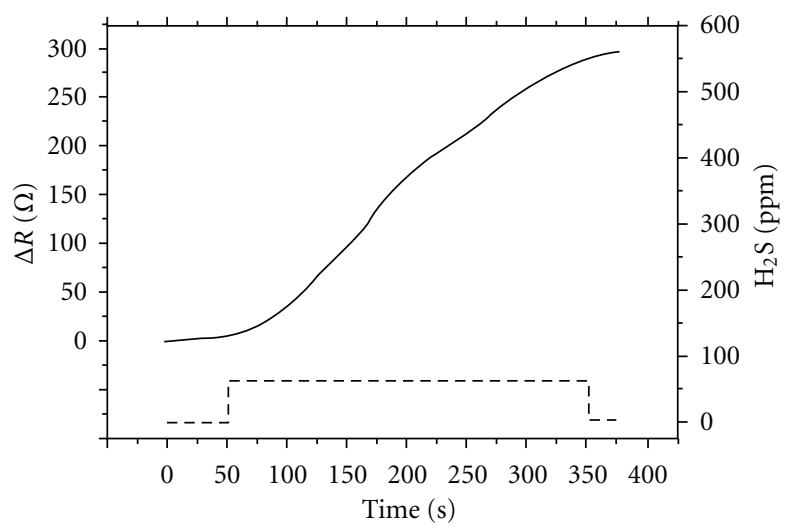

(d)

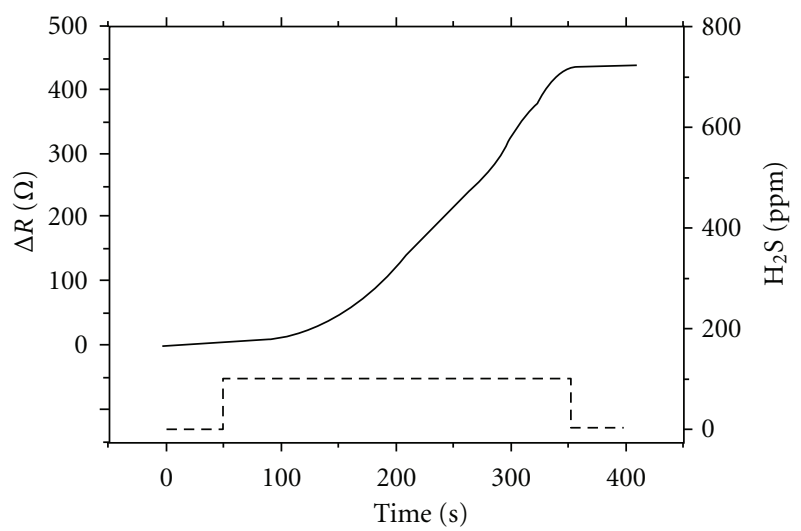

(f)

Figure 4: Curve of the resistance variation $\left(\Delta R=R_{f}-R_{0}\right)$ versus time where $R_{0}$ is the resistance of the sensor exposed to pure $\mathrm{N}_{2}$, and $R_{f}$ is the maximum value of resistance. The $\mathrm{H}_{2} \mathrm{~S}$ concentrations (in $\mathrm{N}_{2}$ ) are: (a) 10, (b) 20, (c) 40, (d) 60, (e) 80, and (f) 100 ppm, respectively.

to $\mathrm{H}_{2} \mathrm{~S}$. The adsorbed gas molecules modify the Au/SWCNT Schottky contact areas and induce instantaneous modulations of the metal contact work function, which changes the device's resistance.

In other words, selective chemisorption of the molecules on $\mathrm{Au}$ and passivation of the $\mathrm{Au} / \mathrm{SWCNT}$ interface are responsible for the measured increase of the contact resistance between $\mathrm{Au}$ and nanotubes.
Considering the strong bonding forces acting between $\mathrm{Au}$ and $\mathrm{H}_{2} \mathrm{~S}$ [22], this interpretation is also able to explain the need of a simultaneous thermal and electrostatic shock (voltage gate) to obtain complete desorption of the gas and recovery of the sensor.

It is to be noted that some papers [22-27] reported about gas sensors assembled with nanotubes decorated by metal nanoparticles. In these systems the metallic species act as 


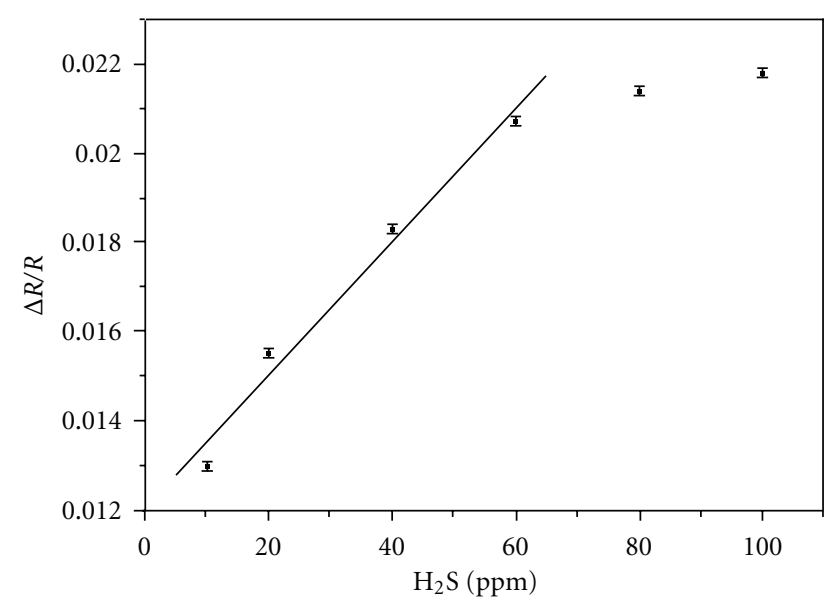

FIGURE 5: Relative resistance change $\left(\Delta R / R_{0}\right)$ for the different $\mathrm{H}_{2} \mathrm{~S}$ concentrations.

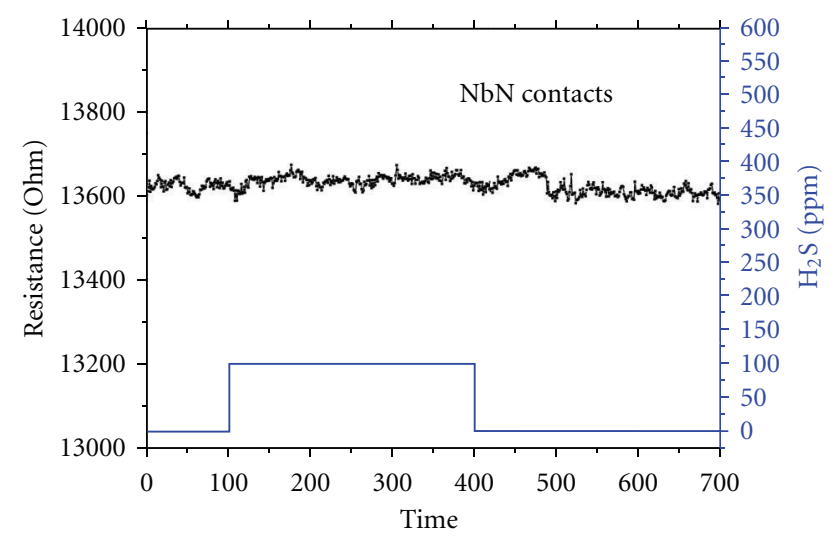

Figure 6: Sensing device fabricated using NbN electrodes: resistance changes upon exposure to $100 \mathrm{ppm}$ of $\mathrm{H}_{2} \mathrm{~S}$.

the sensing materials, and a charge transfer occurs between metal clusters and nanotubes. As regards $\mathrm{H}_{2} \mathrm{~S}$, due to the large amount of metal nanoparticles, very low concentration of the gas could be detected [24-26]. On the other hand, such sensors saturate for gas concentration around $10 \mathrm{ppm}$, a value clearly below the threshold limit that poses serious health risks in workplaces or through accidental exposures.

\section{Conclusions}

We have fabricated two types of gas detectors using the same SWCNT as active material and either $\mathrm{Au} / \mathrm{Cr}$ or $\mathrm{NbN}$ for the electrodes of the multifinger device. The task of ordering the nanotube bundles perpendicularly to the electrodes of the sensors has been pursued by using DEP. The other focal point, that is, the reduction of the recovery time and the optimization of the response time, has been overcome by the combined use of a back gate potential and of a thermal shock.

In the investigated concentrations range (10-100 ppm), the response of the sensor fabricated using $\mathrm{Au} / \mathrm{Cr}$ electrodes is characterized by high level performance in terms of reproducibility and response times.

The accurate detection, at room temperature, of $\mathrm{H}_{2} \mathrm{~S}$ concentrations near to the threshold of health risk makes our devices really useful for in-door and out-door safety applications, including use in coal and natural gas processing, petroleum industries, security monitoring, and biogas production.

The fact that the NbN-based electrodes does not enable to register the presence of the gas suggests the lack of a specific interaction between nanotubes and $\mathrm{H}_{2} \mathrm{~S}$, that is, a poor electron-donor specie. The experiments performed using electrodes fabricated with different materials allowed us to highlight that a mechanism different from a charge transfer between gas molecules and nanotube is responsible for $\mathrm{H}_{2} \mathrm{~S}$ detection. The conductivity changes detected by our circuit are instead likely caused by the Schottky barrier modulation at the metal/SWCNT interface induced by chemisorption of $\mathrm{H}_{2} \mathrm{~S}$ on the Au electrode [28].

It is to be underlined that the operating mechanism of this kind of sensors could represent an attractive approach towards a selectivity based not only on the conventional nanotube functionalization but also on the combination of different electrode materials for manufacturing a multi gas sensor platform. The perturbations of the conductivity induced in the nanotube-based circuit by the chemical interaction of a gaseous species with a selected electrode material give indeed easy to read out direct information. These sensors can be essential components to interface with conventional electronic architectures in a lab-on-chip hybrid system.

\section{References}

[1] N. Sinha, J. Ma, and J. T. W. Yeow, "Carbon nanotube-based sensors," Journal of Nanoscience and Nanotechnology, vol. 6, no. 3, pp. 573-590, 2006.

[2] M. Penza, "Carbon nanotubes for gas sensing applications: principles and transducers," in Carbon Nanomaterials for Gas Adsorbtion, M. L. Terranova, S. Orlanducci, and M. Rossi, Eds., CRC Press, Taylor Francis Group 2012.

[3] D. W. H. Fam, A. Palaniappan, A. I. Y. Tok, B. Liedberg, and S. M. Moochhala, "A review on technological aspects influencing commercialization of carbon nanotube sensors," Sensors and Actuators B, vol. 157, no. 1, pp. 1-7, 2011.

[4] T. Zhang, S. Mubeen, N. V. Myung, and M. A. Deshusses, "Recent progress in carbon nanotube-based gas sensors," Nanotechnology, vol. 19, no. 33, Article ID 332001, 2008.

[5] Y. Wang and J. T. W. Yeow, "A review of carbon nanotubesbased gas sensors," Journal of Sensors, vol. 2009, Article ID 493904, 24 pages, 2009.

[6] D. R. Kauffman and A. Star, "Carbon nanotube gas and vapor sensors," Angewandte Chemie - International Edition, vol. 47, no. 35, pp. 6550-6570, 2008.

[7] M. Lucci, A. Reale, A. Di Carlo et al., "Optimization of a $\mathrm{NO}_{x}$ gas sensor based on single walled carbon nanotubes," Sensors and Actuators B, vol. 118, no. 1-2, pp. 226-231, 2006.

[8] M. Lucci, P. Regoliosi, A. Reale et al., "Gas sensing using single wall carbon nanotubes ordered with dielectrophoresis," Sensors and Actuators B, vol. 111-112, pp. 181-186, 2005. 
[9] M. L. Terranova, M. Lucci, S. Orlanducci et al., "Carbon nanotubes for gas detection: materials preparation and device assembly," Journal of Physics Condensed Matter, vol. 19, no. 22, Article ID 225004, 2007.

[10] M. Salvato, M. Lucci, M. Cirillo et al., "Low temperature conductivity of carbon nanotube aggregates," Journal of Physics Condensed Matter, vol. 23, no. 47, 2011.

[11] J. Suehiro, H. Imakiire, S. I. Hidaka et al., "Schottky-type response of carbon nanotube $\mathrm{NO}_{2}$ gas sensor fabricated onto aluminum electrodes by dielectrophoresis," Sensors and Actuators B, vol. 114, no. 2, pp. 943-949, 2006.

[12] R. Fujii, Y. Gotoh, M. Y. Liao, H. Tsuji, and J. Ishikawa, "Work function measurement of transition metal nitride and carbide thin films," Vacuum, vol. 80, no. 7, pp. 832-835, 2006.

[13] R. Schneider, B. Freitag, D. Gerthsen, K. S. Ilin, and M. Siegel, "Structural, microchemical and superconducting properties of ultrathin $\mathrm{NbN}$ films on silicon," Crystal Research and Technology, vol. 44, no. 10, pp. 1115-1121, 2009.

[14] Iowa State University, Department of Chemistry MSDS, Hydrogen Sulfide Material Safety Data Sheet, http://avogadro .chem.iastate.edu/MSDS/hydrogen_sulfide.pdf.

[15] N. Izadi, A. M. Rashidi, S. Golzardi, Z. Talaei, A. R. Mahjoub, and M. H. Aghili, "Hydrogen sulfide sensing properties of multi walled carbon nanotubes," Ceramics International, vol. 38, no. 1, pp. 65-75, 2012.

[16] M. Lucci, S. Sanna, G. Contini et al., "Electron spectroscopy study in the NbN growth for NbN/AlN interfaces," Surface Science, vol. 601, no. 13, pp. 2647-2650, 2007.

[17] F. Valentini, A. Amine, S. Orlanducci, M. L. Terranova, and G. Palleschi, "Carbon nanotube purification: preparation and characterization of carbon nanotube paste electrodes," Analytical Chemistry, vol. 75, no. 20, pp. 5413-5421, 2003.

[18] J. Kong, N. R. Franklin, C. Zhou et al., "Nanotube molecular wires as chemical sensors," Science, vol. 287, no. 5453, pp. 622$625,2000$.

[19] E. S. Snow, J. P. Novak, P. M. Campbell, and D. Park, "Random networks of carbon nanotubes as an electronic material," Applied Physics Letters, vol. 82, no. 13, pp. 2145-2147, 2003.

[20] J. P. Novak, E. S. Snow, E. J. Houser, D. Park, J. L. Stepnowski, and R. A. McGill, "Nerve agent detection using networks of single-walled carbon nanotubes," Applied Physics Letters, vol. 83, no. 19, pp. 4026-4028, 2003.

[21] L. C. Wang, K. T. Tang, I. J. Teng et al., "A single-walled carbon nanotube network gas sensing device," Sensors, vol. 11, no. 8, pp. 7763-7772, 2011.

[22] D. R. Kauffman, D. C. Sorescu, D. P. Schofield, B. L. Allen, K. D. Jordan, and A. Star, "Understanding the sensor response of metal-decorated carbon nanotubes," Nano Letters, vol. 10, no. 3, pp. 958-963, 2010.

[23] A. Star, V. Joshi, S. Skarupo, D. Thomas, and J. C. P. Gabriel, "Gas sensor array based on metal-decorated carbon nanotubes," Journal of Physical Chemistry B, vol. 110, no. 42, pp. 21014-21020, 2006.

[24] M. Penza, R. Rossi, M. Alvisi et al., "Pt- and Pd-nanoclusters functionalized carbon nanotubes networked films for subppm gas sensors," Sensors and Actuators B, vol. 135, no. 1, pp. 289-297, 2008.

[25] M. Penza, R. Rossi, M. Alvisi, G. Cassano, and E. Serra, "Functional characterization of carbon nanotube networked films functionalized with tuned loading of Au nanoclusters for gas sensing applications," Sensors and Actuators B, vol. 140, no. 1, pp. 176-184, 2009.
[26] S. Mubeen, T. Zhang, N. Chartuprayoon et al., "Sensitive detection of $\mathrm{H}_{2} \mathrm{~S}$ using gold nanoparticle decorated singlewalled carbon nanotubes," Analytical Chemistry, vol. 82, no. 1, pp. 250-257, 2010.

[27] S. Mubeen, J. H. Lim, A. Srirangarajan, A. Mulchandani, M. A. Deshusses, and N. V. Myung, "Gas sensing mechanism of gold nanoparticles decorated single-walled carbon nanotubes," Electroanalysis, vol. 23, no. 11, pp. 2687-2692, 2011.

[28] A. J. Leavitt and T. P. Beebe, "Chemical reactivity studies of hydrogen sulfide on $\mathrm{Au}(111)$," Surface Science, vol. 314, no. 1, pp. 23-33, 1994. 

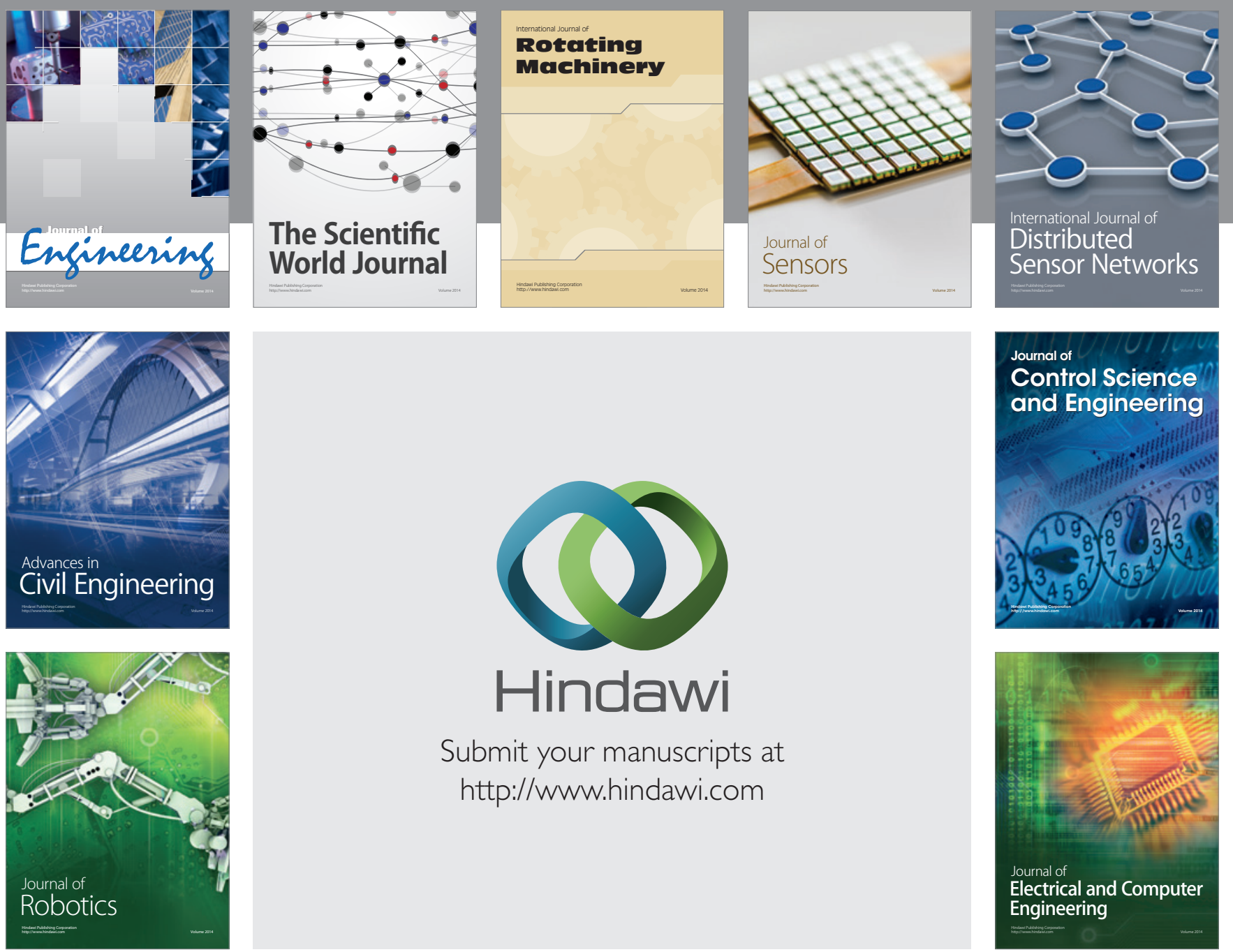

Submit your manuscripts at

http://www.hindawi.com
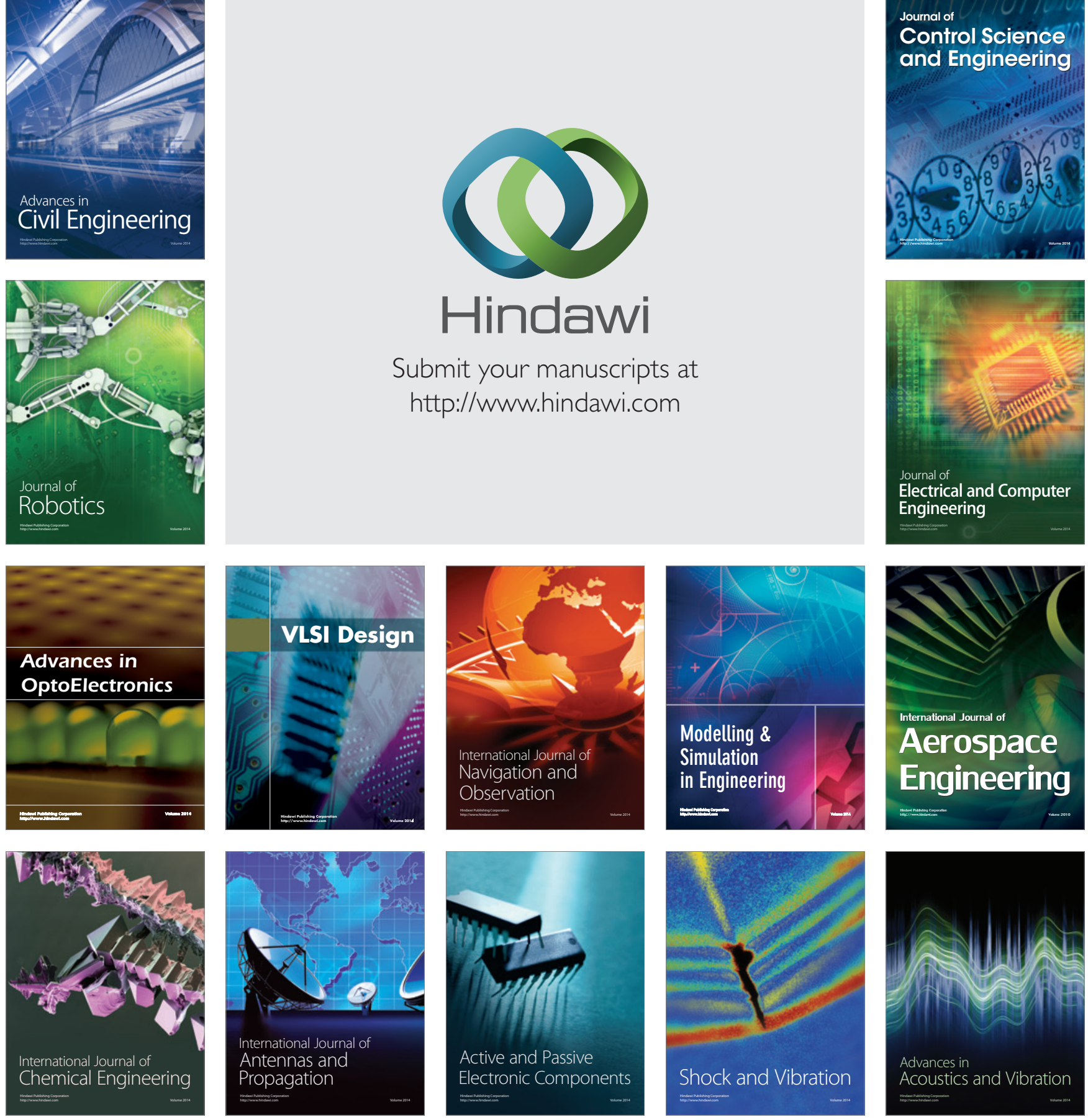